\title{
Dispositivos de Captura Profanação Possível Via Formação de Professores
}

\author{
Roque Strieder ${ }^{1}$ \\ Clenio Lago ${ }^{2}$
}

\begin{abstract}
Resumo
0 contexto político contemporâneo, fortemente marcado pela presença de dispositivos de captura de subjetividades e por um viés biopolítico, basicamente reduz a vida a objeto de cálculos, objeto de técnicas de vigilância e controle. Com base nesse cenário, a reflexão tem como propósito tensionar de que modo, e com quais estratégias, processos formativos podem fazer frente a essa subserviência aos dispositivos de captura das subjetividades. Como suporte desses processos formativos, propomos como pano de fundo epistemológico à complexidade, um convite para que cada uma e todas as áreas de conhecimentos se sintam convidadas para, conversando (cum-versare), contribuírem para uma tomada de decisão em benefício do redimensionamento da identidade e da dignidade da pessoa humana. Trata-se de uma busca em referenciais teóricos, e basicamente com Agamben, a busca de uma alternativa para a "formação que vem" que tenha na profanação a capacidade dinâmica de articular diferentes usos para os temas curriculares; usos como potencializadores da autonomia.
\end{abstract}

Palavras chave: Biopolítica. Processos Formativos. Profanação.

\section{CAPTURE DEVICES: POSSIBLE PROFANATION BY TEACHERS' TRAINING}

\section{ABSTRACT}

The contemporary political context, strongly characterized by the presence of subjectivities capture devices and one biopolitical bias, basically it reduces the life to object of calculations, to object of monitoring and control techniques. Based on this scenario the reflection aims to tense in what way and with which strategies, training processes can cope with this subservience to the capture devices of the subjectivities. As a support of these training processes we propose as epistemological background the complexity, an invitation to each one and all

1 Doutor em Educação e docente na área de Ciências Humanas - vinculado ao Programa de Mestrado em Educação da Unoesc. roque.strieder@unoesc.edu.br

2 Doutor em Educação e docente na área de Ciências Humanas - vinculado ao Programa de Mestrado em Educação da Unoesc. clenio.lago@unoesc.edu.br 
the areas of knowledge feel themselves invited to, conversing (cum-versare) they contribute for one decision-making in benefit of the resizing of the identity and dignity of the human person. It is a search for theoretical references, and basically to Agamben, the search for an alternative to the 'formation that is' who has the desecration dynamic ability to articulate different uses for curricular themes, uses as potentializers of autonomy

Keywords: Biopolitics. Training Processes. Profanation. 
É prudente reconhecer a complexa e profunda situação de crise existencial, crise formativa, crise produtiva e ecológica que emerge, envolve e está presente na sociedade contemporânea; crises que levam a uma condição humana que, cercada de desencanto, persiste alimentada pela sensação de vazio interior, uma efetiva potencializadora do aumento da ansiedade e da angústia que, por sua vez, se traduzem em situações de estresse, depressão e outras enfermidades psicossomáticas de toda ordem. A redução da vida ao eficientismo tecnológico, ao utilitarismo, às metas a serem alcançadas, ao constante controle e vigilância pela técnica, alia-se com a fragilização das esperanças, com o distanciamento do horizonte de crenças e a incapacitação de opções profundas de sentido humano, político e cultural.

Em um contexto humano e social tão díspare, tão amplo e complexo, nenhum mecanismo de formação localizado em proposições, visando a soluções simplistas, poderá ter êxito. É, certamente, relevante acolher, como inerente às reflexões e ações formativas, o "princípio de incompletude", ou Teorema de Gödel; princípio pelo qual a ciência contemporânea reconhece que nenhum sistema lógico é inteiramente capaz de fundar-se a si mesmo, pois precisará de suportes e axiomas que lhe são exteriores. Significa reconhecer pedagogicamente, e em termos de formação de professores, como várias ciências já o fizeram, um grau de desconfiança em relação às realidades, sejam elas físicas, culturais, humanas ou formativas.

A formação de professores já não pode ser olhada e realizada na miopia reducionista nem como um dispositivo para capturar subjetividades. Importa envolver diferentes suportes teóricos e filosóficos, sobre as mais diversas dimensões do ser humano, situados em um determinado tempo e espaço vital, cujas luzes, mesmo que brilhantes, são relativas e nebulosas.

A formação de professores, longe de se tratar de uma preocupação movida por questões emocionais, sensitivas ou afetivas, exige visualização e localização dentro do giro antropológico que caracterizou a modernidade, regada com as mutabilidades inferidas pela pós-modernidade e pela contemporaneidade. É 
preciso estar ciente de que uma oferta formativa alheia a esses contextos é, muitas vezes, entendida como não necessária. É prudente, no atual contexto, uma insurreição de saberes.

Para uma efetiva implementação de uma diferente dinâmica formativa, é aconselhável considerar o diálogo com as várias áreas de conhecimentos, seja a filosofia, a antropologia, a biologia, a psicologia, a sociologia, entre outras. A prudência formativa também convida para consolidar insatisfação, inconformismo e profanação diante das frias lógicas de governar vidas, como a biopolítica, o biopoder, os dispositivos técnicos de controle e de captura das subjetividades, bem como a governamentalidade.

A atualidade contemporânea está impregnada de dispositivos que, além de ordenarem as rotinas da vida social, formatam a vida individual de tal maneira que já não é possível localizar-se uma unidade no contexto das diversas formas-de-vida assumidas. Para Agamben (2015), o contexto atual é marcado pela dissolução da vida em diversas formas-de-vida, ou seja, a vida está presa a rótulos variáveis de acordo com a situação em que o sujeito se encontra. Gordo ou magro, professor ou bombeiro, sexualmente como hetero, homo, bi ou pansexual, entre tantas outras formas que, diante da diversidade, impossibilitam a unidade do sujeito em uma forma-de-vida. Uma unidade como forma-de-vida, contraposta à multiplicidade, é uma aposta de Agamben desejando mostrar ser possível e mesmo necessário instaurar um diferente uso das coisas do mundo; uso capaz de romper com a estrutura lógica dos dispositivos, ou seja, uma profanação dos dispositivos.

Aproximar os debates e as reflexões dessa diversidade de entradas é uma forma de fecundar a sintonia com a dinâmica das convergências, tão presentes na atualidade, nas ciências da natureza e nas ciências sociais. No interstício dessas convergências é possível diagnosticar melhor a preocupante situação da condição humana como também sinalizar estratégias alternativas possíveis, via processos formativos.

Assim, a reflexão tem como propósito tensionar de que modo, e com quais estratégias, processos formativos podem fazer frente ao raso saber-fazer mercantilista e de subserviência aos dispositivos de captura das subjetividades. 
Supõe-se relevante a proposição de um diferente pano de fundo epistemológico em que cada uma e todas as áreas de conhecimentos se sintam convidadas para, conversando (cum-versare), contribuírem para uma formação capaz de contemplar todas as dimensões do ser humano. Esse fundo epistemológico requer a construção de um diferente caminho que, segundo Agamben (2006, p. 11), é um "caminho que o pensamento deve ainda percorrer [...] e se faça em direção à uma ética". Trata-se de uma busca em referenciais teóricos que, segundo Marconi e Lakatos (2008), não são uma mera repetição do que já fora escrito sobre um determinado assunto, mas uma investigação de um tema sob diversos enfoques para chegar a conclusões diferentes. E, como toda atividade de pesquisa é colaborativa e estávamos no encalço de passos seguidos por outros pensadores, nos beneficiamos de seus trabalhos e princípios e, porque não dizer, de suas práticas.

\section{No Invólucro dos Dispositivos}

A civilização humana está em crise. Aonde chegou, o bem-estar material, não necessariamente, trouxe o bem-estar mental, afetivo e relacional. Prova disso são os consumos desenfreados de drogas, ansiolíticos, antidepressivos e remédios para dormir. O desenvolvimento econômico não trouxe o desenvolvimento moral e ético. A aplicação do cálculo, da cronometria, da biometria, da hiper-especialização, da compartimentalização do trabalho, impostos às empresas, às repartições públicas e às nossas vidas, trouxeram também a degradação das solidariedades, a burocratização generalizada, a competição exacerbada, a perda de iniciativa, o medo da responsabilidade, o silenciamento e a dessubjetivação. A disseminação dos mecanismos e dispositivos disciplinares, dispositivos linguísticos conceituais, aliados aos mecanismos de segurança e à biopolítica, amplia o poder sobre a vida - o biopoder.

A lógica mercadológica, a biopolítica e o biopoder reduzem a vida e a vida dos seres humanos a objetos biométricos, constantemente vigiados e controlados por dispositivos da tecnociência e práticas de governamentalidade, visando à captura, ao uso e à tutelagem das subjetividades. 
Na perspectiva da governamentalidade os dispositivos são uma espécie de máquina cuja função é manter a ordem constituída a qualquer preço. Na lógica dessa prática, o dispositivo, de acordo com Agamben (2010, p. 38), "nomeia aquilo em que e por meio do qual se realiza uma pura atividade de governo sem fundamento no ser. Por isso os dispositivos devem sempre implicar um processo de subjetivação, isto é, devem produzir o seu sujeito"; a formação de subjetividades capturadas é ela própria capturantes, visto que os mecanismos biopolíticos e do biopoder constituem as subjetividades.

$\mathrm{Na}$ Grécia antiga duas expressões eram usadas para designar a vida: zoé (vida nua) referente à vida biológica, comum entre humanos e animais; bios, significando a vida especificamente humana com dimensões moral e política - o viver próprio de um indivíduo ou de um grupo de indivíduos. Bios se referia à vida qualificada e não à mera vida natural, a zoé. Desse modo, a finalidade não é o simples viver, mas o viver bem.

A partir da modernidade, a zoé, a vida nua, a sua condição física e mesmo a saúde dos seres humanos, que em períodos anteriores estavam confiados aos âmbitos privados da família, passa a ser preocupação da pólis - Estado. Por sua vez, a bios, a dimensão moral e política, antes do âmbito público fica, a partir da modernidade, reduzida a técnicas desenvolvidas por especialistas, agora com caráter privado, ou seja, restritas a questões da consciência de cada indivíduo (Agamben, 2002).

A submissão da zoé, da vida que os humanos têm em comum com os animais, com a soberania e com o poder do Estado, se faz possível pelo desenvolvimento de estratégias políticas para a sua gestão. Esse conjunto de estratégias de gestão é denominado por Foucault de biopoder e biopolítica.

A biopolítica (Foucault, 1999) é um fenômeno que formula a articulação entre a anatomopolítica dos corpos, uma característica dos mecanismos disciplinares, com uma biopolítica das populações, como característica dos mecanismos de regulação e segurança. Um poder a ser produzido a partir do saber sobre a vida, uma espécie de investimento maciço sobre a vida e seus fenômenos, a partir de uma tecnologia métrica que transforma a população em objeto de intervenção política, em objeto de gestão e de governamentalidade. Para Foucault, "essa 
tecnologia de poder, essa biopolítica, vai implantar mecanismos que têm certo número de funções muito diferentes das funções que eram as dos mecanismos disciplinares" (2005, p. 293).

Ainda segundo Foucault (2005), a tecnologia biopolítica não tem o corpo individual como objeto e objetivo. É uma tecnologia que se dirige e se aplica ao ser humano enquanto ser vivo, enquanto espécie, ou seja, enquanto população. À medida que a disciplina pretende agir e penetrar o corpo do indivíduo em seus detalhes, a biopolítica se direciona para a massa humana, uma forma de modular as inúmeras variáveis que afetam a população. A lógica disciplinar usa, como recurso principal, a vigilância, e a lógica biopolítica recorre a dispositivos reguladores de aspectos da vida das populações, como taxas de natalidade, de saúde, de morbidade, de envelhecimento, de mortalidade, entre outros.

Foucault (2008), em "Segurança, Território, População", descreve "população", no contexto da biopolítica, como um conjunto de seres vivos e coexistentes, possuidores de traços biológicos e patológicos particulares. A função do poder via biopolítica não é mais matar, mas investir sobre a vida. É essa abordagem que Foucault descreve no último capítulo "Direito de morte e o poder sobre a vida", em "História da sexualidade I: a vontade de saber". Para Foucault (1999, p. 130), "o velho direito de causar a morte ou deixar viver foi substituído por um poder de causar a vida ou devolver à morte". Nesse contexto, declina o poder dos pais de família romana de dispor da vida dos filhos e dos escravos e mesmo o privilégio do soberano sobre o direito da vida e morte de seus súditos. Do poder absoluto de causar a morte ascende o poder de causar a vida. Uma forma de desqualificar a morte e fixar o poder sobre a gestão da vida.

No "Em Defesa da sociedade", Foucault afirma que o biopoder disciplina os corpos via escolas e exército, e regula a população a partir da demografia, do controle das riquezas.

Nas palavras de Foucault,

Esse novo tipo de poder, que já não é, pois, de modo algum transcritível nos termos de soberania, é, acho eu, uma das grandes invenções da sociedade burguesa. Ele foi um dos instrumentos fundamentais da implantação do ca- 
pitalismo industrial e do tipo de sociedade que lhe é correlativo. Esse poder não soberano, alheio, portanto, à forma da soberania, é o poder "disciplinar" (2005, p. 43).

Assim, o biopoder passa a ser um elemento fundamental para o desenvolvimento capitalista, cuja eficácia produtiva depende da docilidade dos corpos. O controle sobre os corpos, e sua redução a máquinas de produção, possibilita extrair dos corpos o máximo de tempo e de trabalho e ajusta a população aos processos econômicos.

Segundo Candiotto e D’Espíndula (2012, p. 23), o biopoder “não é uma política sobre a vida ou uma política da vida, mas uma gestão que a torna um meio economicamente rentável e utilizável para a perpetuação de um processo de dominação". Já a concepção de governamentalidade, desenvolvida por Foucault (2008) na quarta lição do Curso Segurança, território, população, no Collège de France, em 1978, designa, segundo Machado (1992, p. XXIII), um conjunto de práticas de governo que "têm na população seu objeto, na economia seu saber mais importante e nos dispositivos de segurança seus mecanismos básicos”.

Quanto à significação de dispositivo, faremos uso das reflexões expressas nas produções de Agamben, uma vez que assume e amplia a proposta conceitual de dispositivo desenvolvida por Foucault. Em entrevista concedida a Alain Grosrichard, Foucault (2009, p. 244), respondendo à pergunta "Para você qual é o sentido e a função deste termo: dispositivo?", destaca três aspectos conceituais. Os dois primeiros referem-se aos dispositivos como forças de sacralização que não permitem questionamentos tampouco uma vivência plena da liberdade individual. Na terceira concepção de dispositivo, porém, o autor destaca uma possibilidade de abertura, um espaço para uma reinterpretação dos valores, ou seja, a existência de uma força de profanação e reinvenção: "Em terceiro lugar, entendo dispositivo como um tipo de formação que, em determinado momento histórico, teve como função principal fornecer uma resposta àquilo que não pode esperar" (2009, p. 244).

O filósofo italiano Agamben, ao realizar uma genealogia da expressão dispositivo, elucida a abrangência do termo em Foucault e também em Hegel, bem como da proximidade desse termo com a oikonomia (administração/ges- 
tão da oikos = casa) feita pelos teólogos no decorrer da Idade Média. Afirma Agamben (2010, p. 39) que oikonomia é "um conjunto de práxis, de saberes, de medidas, de instituições cujo objetivo é gerir, governar, controlar e orientar, num sentido que se supõem útil, os gestos e os pensamentos dos homens." Em seguida, olhando os dispositivos como uma forma de poder que captura as subjetividades, Agamben (2010, p. 40-41) chama de

\begin{abstract}
dispositivo qualquer coisa que tenha de algum modo a capacidade de capturar, orientar, determinar, interceptar, modelar, controlar, e assegurar os gestos, as condutas, as opiniões e os discursos dos seres viventes. Não somente, portanto, as prisões, os manicômios, o panóptico, as escolas, as confissões, as fábricas, as disciplinas, as medidas jurídicas, etc., cuja conexão com o poder é em um certo sentido evidente, mas também a caneta, a escritura, a literatura, a filosofia, a agricultura, o cigarro, a navegação, os computadores, os telefones celulares e - porque não - a linguagem mesma, que é talvez o mais antigo dos dispositivos, em que há milhares e milhares de anos um primata - provavelmente sem dar-se conta das consequências que se seguiriam - teve a inconsciência de se deixar capturar.
\end{abstract}

Para Agamben (2010), a lógica capitalista, potencializada pela tecnociência, faz com que, na contemporaneidade, todo e qualquer instante da vida dos indivíduos seja modelado, contaminado e controlado por algum dispositivo.

Diante da biopolítica, do biopoder, da governamentalidade e dos dispositivos invasores e de captura das subjetividades, o que fazer? Como reagir? Existe alguma permeabilidade nos dispositivos técnicos de captura que possibilita "restituí-los a um possível uso comum?" (Agamben, 2010, p. 44). Que estratégias, que consensos formativos possibilitam emancipar a subjetividade capturada pelos dispositivos, para devolver ao ser humano a arte de viver, a da infância, "já que as crianças sabem jogar e brincar, enquanto os adultos sérios perderam a capacidade de ser mágicos e de fazerem milagres"? (Agamben, 2007, p. 13). Que níveis de insatisfação, de inconformismo e desacomodação podem levar à dissidência e desejar, como sonha Agamben, uma "política que vem?", uma “comunidade que vem?”, um "ser humano que vem?" e, quem sabe uma "formação que vem...?" Como essas dissidências podem ser pensadas e efetivadas sabendo que: "o fato é que, segundo toda a evidência, os dispositivos 
não são um acidente no qual os homens caíram por acaso, mas eles têm a sua raiz no mesmo processo de 'hominização' que tornou 'humanos' os animais que classificamos sob a rubrica homo sapiens" (Agamben, 2010, p. 43). Para Agamben, não basta destruir os dispositivos, nem usá-los de "modo correto", como sugerem alguns ingênuos, pois os dispositivos "fabricam" os seres humanos. A alternativa é a profanação, mas profanar o quê? Que bases epistemológicas permitem uma formação de professores capacitando-os para a profanação?

\section{Ensonhamentos ${ }^{3}$ Formativos}

Nesse momento vamos reforçar a importância de compreender o pensar complexo como base capaz de fundamentar os processos de formação de professores na atualidade contemporânea, qualificando-os para a profanação. Uma formação profanadora, porque capaz de configurar uma revolução que faça cessar os mecanismos mantenedores dos dispositivos de controle; Que forneça subsídios para a confecção de uma nova função utilitária para as coisas, pois, como afirma Agamben (2007, p. 7), “a criação de um novo uso só é possível ao homem se ele desativar o velho uso, tornando-o inoperante."

A complexidade, como sustento formativo, potencializa a possibilidade de reconhecer a educação escolar, proposta pela modernidade, como um dispositivo disciplinar e do biopoder, para, então, fazer indicativos, a partir de Agamben, sobre contemporaneidade e profanação.

A lógica da modernidade mecanicista de ver a realidade do mundo, da vida e do ser humano orientou as concepções da educação escolar e foi levada para dentro da sala de aula. Significa que a educação escolar foi baseada no modelo clássico da ciência. Na atualidade contemporânea, a evolução da ciência sinaliza limites e insuficiências na descrição das realidades, a partir da ciência clássica. $\mathrm{O}$ reconhecimento da existência de realidades complexas exige uma multiplicidade de conceitos e teorias para formar modelos explicativos. Como

3 Segundo Carlos Castañeda (2007), um sonho lúcido e consciente, abertura para diferentes e evolutivas visões de mundo. 
os seres humanos constituem e são constituídos por essas realidades complexas, é coerente que a educação escolar procure assentar-se nessa base científica que evidencia a incompletude e a diversidade, e também como potencial pedagógico, visando a uma mudança de mentalidade que possibilita a profanação. Para Morin:

A realidade está, desde então, tanto no elo como na distinção entre o sistema aberto e o seu meio. Esse elo é absolutamente crucial tanto no plano epistemológico, como no metodológico, teórico, empírico. Logicamente, o sistema só pode ser compreendido ao incluir nele o meio, que lhe é simultaneamente íntimo e estranho e faz parte dele próprio sendo-lhe sempre exterior (2001, p. 33).

No contexto de realidades dinâmicas, em profunda interdependência com os fazeres humanos, a formação pedagógica tem como pressuposto que cada ser humano se encontra interconectado com uma natureza que é sistêmica, envolvido em uma trama social e cultural também complexa e sistêmica.

A concepção de complexidade implica um processo de conhecimento que envolve as relações construídas em coletivos de individualidades, em contextos como se estivessem imbricados formando uma malha, um algo tecido junto, e no qual cada pessoa, cada manifestação cultural e cada conhecimento, somente faz sentido ou é útil por causa das outras. Bateson (1989, p. 38) assim manifesta-se no diálogo com sua filha: “[...] todo o conhecimento está como se fosse um tricô, ou uma malha, como se fosse um tecido, e que cada peça do conhecimento só faz sentido ou é útil por causa das outras peças". O pensamento complexo é um convite para olhares que desestabilizam, que provocam fissuras, que causam irritação e clamam para o inconformismo para fugir das naturalidades, das acomodações conservadoras e dos dispositivos de captura das subjetividades. Esse pensar complexo também convida para perceber a complexidade humana e, para Morin (2003, p. 49), "O conhecimento da complexidade humana faz parte do conhecimento da condição humana; e esse conhecimento nos inicia a viver, ao mesmo tempo, com seres e situações complexas".

Segundo Assmann e Mo Sung (2001, p. 81), 
Quando as pessoas têm uma visão sistêmica da realidade social conseguem perceber que elas são o que são porque fazem parte de um todo social e que elas não existiriam sem a existência de outras pessoas e do sistema social. Elas conseguem perceber que o que afeta uma pessoa ou grupos sociais ou a natureza, que é o meio onde o sistema social reproduz a sua vida, afeta a si próprio e ao seu grupo. Porque nós todos estamos interligados [...] É a interdependência como um fato (grifos nossos).

Como interdependentes, não habitamos o mundo na condição de indivíduos, mas convivemos com os demais seres humanos e os contextos sociais ecológicos construídos pelas diversas identidades distintas conectadas entre si. Um convívio será tanto mais dinâmico e saudável quanto mais oportunizar o respeito, mesmo àqueles com maiores dificuldades ou facilidades. Reconhecer as diferenças, permitindo a acolhida do outro e não mais sua dessubjetivação, passa pela mudança de mentalidade a ser iniciada na interioridade de cada ser humano para ser exteriorizada e estendida a todos os humanos. Interioridade e exterioridade indistinguíveis tal qual é indistinguível o interior e o exterior de uma banda de Moebius, ${ }^{4}$ posto que existentes em continuidade e partes de um mesmo espaço topológico. Somente uma questão temporal pode diferenciar interior e exterior porque eles se encontram separados pelo tempo que se leva para fazer uma volta suplementar ao longo da fita.

É nesse sentido que a formação de professores precisa realizar uma esperada mudança de mentalidade, concebendo os processos pedagógicos como um

conjunto de interfaces comunicativas entre agentes cognitivos que constituem um sistema aprendente ou uma organização aprendente. [Seu] objetivo fundamental é criar e manter uma ecologia cognitiva na qual possam emergir experiências de aprendizagem. Trata-se de um mergulho coletivo numa seqüência de processos auto-organizativos da vida dos aprendentes, à luz do princípio de que existe uma coincidência básica entre processos vitais e processos cognitivos (Assmann, 1998, p. 176).

\footnotetext{
${ }_{4}$ A banda de Moebius é um tipo especial de superfície onde não há lado de dentro ou de fora, ou seja, nela apenas há um lado e uma única borda que é uma curva fechada. A banda foi descoberta pelo astrônomo e matemático alemão August Ferdinand Moebius (1790-1868).
} 
Se processos pedagógicos reconhecem a interdependência entre processos formativos, processos vitais e processos cognitivos, a formação de professores sinaliza para a importância da teorização sobre a educação, a importância da reflexão sobre o ato educativo e a formulação de proposições para diferentes experiências de vida. A pedagogia é um campo de saberes sobre a educação, um campo de saberes sobre as experiências vivenciais que a envolvem. Ainda, a pedagogia é um processo reflexivo para compreender a educação e as formas pelas quais os humanos identificam, (re)elaboram e fomentam entre si e nos outros, aspectos culturais a serem apropriados para a preservação da espécie humana, produzidos historicamente pelas diferentes gerações.

Cada ser humano, ao nascer, se encontra em um mundo, se encontra em um contexto cultural e social, e a educação é o processo que possibilita incluir os que chegam. Ou seja, como assevera Arendt,

A educação é o ponto em que decidimos se amamos o mundo o bastante para assumirmos a responsabilidade por ele e, com tal gesto, salvá-lo da ruína que seria inevitável não fosse a renovação e a vinda dos novos e dos jovens. A educação é, também, onde decidimos se amamos as nossas crianças o bastante para não expulsá-las do nosso mundo e abandoná-las a seus próprios recursos, e tampouco arrancar de suas mãos a oportunidade de empreender alguma coisa nova e imprevista para nós, preparando-as em vez disso com antecedência para a tarefa de renovar um mundo comum (2009, p. 247).

Iniciada com as proposições de Comenius, nos primórdios da modernidade a pedagogia se consolidou "como um dispositivo de intervenção e controle da vida social e individual dos sujeitos e como dispositivo de reprodução do poder" (Díaz, 1998, p. 23). Então, as ações educativas convergem para aspectos da vida dos indivíduos e da população. Na perspectiva disciplinar visa a produzir nos indivíduos uma autovigilância, uma forma de evitar comportamentos de riscos e, em uma perspectiva biopolítica, objetiva a prevenção, e o alvo é a população.

Disciplina e biopolítica são verdades com caráter de pureza, atemporais, absolutas e estáveis; verdades que autorizam os professores a submeter os alunos, uma vez que o professor possui a verdade sobre o ensino e sobre o que aprender. São as verdades desses dispositivos de intervenção e controle 
social que firmam relações de interesse, poder e secularizações. Essas verdades confiscam espaços, gestos e significados da esfera do comum para um patamar sagrado, o intocável. A educação escolar fica, prioritariamente, entendida como um ambiente que se retira da esfera das experiências humanas e socioculturais para ser elevado a um pedestal sagrado, uma espécie normatizada, autônoma e secularizada. Nessa educação, a técnica institucional e formativa centra-se nos corpos dos indivíduos, que passam a ser distribuídos, organizados, treinados e exercitados para serem úteis e dóceis. Uma vez reduzidos a esse racionalismo, serão facilmente vigiados, hierarquizados e disciplinados.

Segundo Agamben (2010, p. 41), é esse indivíduo cegado que resulta da relação entre "os seres viventes (ou as substâncias) e os dispositivos", nos quais é incessantemente capturado; um sujeito que somente poderá ser contemporâneo, e viver a e na contemporaneidade, se não se deixar cegar pelas luzes do século, como oportunidade para mergulhar em sua íntima obscuridade. Segundo Agamben (2010, p. 65), esse sujeito precisa "perceber no escuro do presente essa luz que procura nos alcançar e não pode fazê-lo, isso significa ser contemporâneo". Ser contemporâneo é não ser cegado pelas luzes, é conseguir "entrever nessas a parte da sombra, a sua íntima obscuridade" (Agamben, 2010, p. 64). Ser contemporâneo é dar-se a oportunidade para perceber "o escuro de seu tempo como algo que lhe concerne e não cessa de interpelá-lo [...] é aquele que recebe em pleno rosto o facho de trevas que provém do seu tempo" (Agamben, 2010, p. 64).

Nesse contexto e exigências, novamente um espaço topológico - a banda de Moebius - onde luzes e penumbra se entrevisitam em escala temporal, o próprio Agamben admite que ser contemporâneo não é fácil, "é, antes de tudo, uma questão de coragem", e escreve: “os contemporâneos são raros" (2010, p. 65).

A estratégia alternativa, proposta por Agamben, de saída desse labirinto temporal - a contemporaneidade -, é a disponibilização das coisas para um livre-uso, como condição para que não mais sejam formatadoras da vida. Na perspectiva de fundamentar a formação de professores, profanar será uma experiência que não mais procura satisfazer o desejo da alienação, mas capaz de preencher as várias dimensões do ser humano. Se, como escreve Agamben (2007, p. 75), 
"Profanar não significa simplesmente abolir e cancelar as separações, mas fazer delas um uso novo, a brincar com elas", essa formação será uma experiência lúdica. Profanar significa trazer as coisas de volta à possibilidade de um uso lúdico, permitindo que o sujeito - o professor - se transforme naquilo que mais propriamente ele é, livrando-se das amarras impostas pelos dispositivos para, então, construir-se como persona ${ }^{5}$, sua forma-de-vida.

A "profanação do improfanável” (Agamben, 2007, p. 79), base da política formativa de professores, é uma questão ética como possibilidade de criar uma forma-de-vida capaz de superar os dispositivos de controle social e educacional. Desenvolver a capacidade de atribuir novos usos das temáticas curriculares que já existem e, consequentemente, poder criar novas, com funções também novas, é apontada como uma forma para realizar profanações, "já que se trata de liberar o que foi capturado e separado por meio dos dispositivos e restituí-los a um possível uso comum" (Agamben, 2010, p. 44). Profanar significa restituir ao livre-uso comum o que havia sido separado na esfera do sagrado, ou seja, pertencia aos deuses. "Consagrar (sacrare) era o termo que designava a saída das coisas da esfera do direito humano, profanar por sua vez, significava restituí-las ao livre uso dos homens" (Agamben, 2007, p. 65). Agamben compreende como profanas as palavras do jurista romano: "Profano" - podia escrever o grande jurista Trebácio - "em sentido próprio denomina-se aquilo que, de sagrado ou religioso que era, é devolvido ao uso e à propriedade dos homens" (2007, p. 59). Assim, profanar significa uma restituição e não uma forma de expropriação.

Ao retomar a obra de Walter Benjamin, "O capitalismo como religião", Agamben (2007, p. 70) entende o capitalismo como, "essencialmente, um fenômeno religioso, que se desenvolve de modo parasitário a partir do cristianismo". O capitalismo já não é mais somente uma secularização da fé protestante, mas uma manifestação religiosa desenvolvida de maneira paralela e como condição de existência do próprio cristianismo. É em um templo, que Agamben denomina de museu, no qual se celebra a religião capitalista, que ocorre a separação do ser humano com o que ele tem de humano. O ser humano fica órfão de sua

5 Segundo Agamben (2010, p. 61) “[...] persona a 'personalidade' que define o lugar do indivíduo nos dramas e nos ritos da vida social, [...] a capacidade jurídica e a dignidade política do homem livre." 
dignidade humana e torna-se um simples produto, que se vende ou se descarta em qualquer momento. Museu, nesse sentido, não se refere a um "espaço físico determinado, mas a dimensão separada para a qual se transfere o que há um tempo era percebido como verdadeiro e decisivo, e agora já não o é" (2007, p. 73). A dignidade humana, a experiência de vida humana, a condição bios, encontram-se sacralizadas em um museu "na medida em que esse termo indica simplesmente a exposição de uma impossibilidade de usar, de habitar, de fazer experiência" (2007, p. 73).

Profanar e ser contemporâneo são estratégias de Agamben (2010, p. 59), que alerta:

\begin{abstract}
A contemporaneidade, portanto, é uma singular relação com o próprio tempo, que adere a este e, ao mesmo tempo, dele toma distâncias; mais precisamente, essa é a relação com o tempo que a este adere através de uma dissociação e um anacronismo. Aqueles que coincidem muito plenamente com a época, que em todos os aspectos a esta aderem perfeitamente, não são contemporâneos porque, exatamente por isso, não conseguem vê-la, não podem manter fixo o olhar sobre ela.
\end{abstract}

Assim, todo e qualquer processo formativo estará oscilante entre a proximidade e o distanciamento. Ambos pertencem a um espaço topológico temporal, um tempo que, vivido pelo ser professor, alimenta em si diferentes possibilidades para se viver na contemporaneidade. Distanciar-se da realidade sinaliza não interiorização completa. Significa a existência de fissuras, de espaços abertos que podem ser preenchidos por experiências sem a obrigatoriedade de transformar sujeitos que vivem na contemporaneidade em contemporâneos. É também um indicativo de que mesmo um professor, presente e participativo nos processos de formação, seja um sujeito capaz de profanar.

Ainda assim, é importante desenvolver a capacidade da profanação como oportunidade de conceber diferentes formas de uso. Agamben (2007, p. 66) afirma: "Profanar significa abrir a possibilidade de uma forma especial de negligência, que ignora a separação, ou melhor, faz dela um uso particular". Para Agamben, o contato, o toque, o jogo, o lúdico, o brincar, o uso, são meios para profanar as separações. Deve-se fazer outro uso das coisas e das experiências 
formativas para, como enfatiza Agamben, estabelecer uma forma de relacionamento social que elimine a separação instaurada pelo capitalismo e que restitua ao domínio humano o que o sistema aliena para o plano do sagrado. Numa palavra, é preciso profanar e, diante dos dispositivos que sacralizam sistemas culturais e formativos, a formação de professores precisa sensibilizar e firmar diferentes usos, (re)inventar e profanar restituindo-os à esfera humana, ao uso comum, ao ser humano.

É esse profanar que pode des-disciplinar a educação convidando-a para olhares múltiplos reconhecendo a diversidade das formas de tratar de temáticas, reconhecer a multiplicidade das experiências de vida para consigo, para com os outros e para com as realidades do mundo. Na finalização de seu livro Homo Sacer, e referindo-se à política, à filosofia, às ciências médico-biológicas e à jurisprudência, Agamben (2002, p. 194) escreve: "será preciso verificar como, no interior das fronteiras destas disciplinas algo como uma vida nua possa ter sido pensado, e de que modo, em seu desenvolvimento histórico, elas tenham acabado por chocar-se com um limite além do qual elas não podem prosseguir, a não ser sob o risco de uma catástrofe biopolítica sem precedentes."

Na voz de Agamben (2007, p. 79), a formação de professores pode ser o potencializador profanatório de "arrancar dos dispositivos - de todo dispositivo - a possibilidade de uso que os mesmos capturaram." E, diante das coisas e situações consideradas improfanáveis, Agamben conclui, "a profanação do improfanável é a tarefa política da geração que vem”. Uma política que transforma o ser humano a viver em uma pólis, para resolver tudo mediante a linguagem. É essa a comunidade perfeita definida por Aristóteles: o simples fato da vida ser vivida como politicamente qualificada: "Formada a princípio para preservar a vida, a cidade subsiste para assegurar a vida boa" (Aristóteles, 1252b, p. 29-30). Para Aristóteles, a pólis nasce dessa oposição entre viver zoé (vida nua) e viver bem bios (dentro da ordem política), ou seja, uma dinâmica entre a vida e a boa vida.

Por fim, compreendemos a formação de professores como um convite para reflexões e profanações que permitam o reconhecimento dos limites curriculares de uma educação tecnicista e pautada em resultados. Como 
propõe Agamben, a profanação devolve ao humano o que é destinado apenas aos deuses, ou seja, faz retornar aos sujeitos o que é apartado pelos dispositivos.

Desativar os dispositivos de seu lugar costumeiro e invertê-los libera as possibilidades de uso que eles impedem. Importa encontrar formas de profanação no improfanável simplismo e utilitarismo educacional, romper com a lógica tradicional moderna, romper com o medo para instituir o diálogo, o reconhecimento, a compreensão, a superação da alienação; estabelecer enfim a linguagem, é tarefa da revolução.

Resistir e profanar o embrutecimento propiciado pela lógica escolar que somente pode proporcionar a assimilação mecânica de conceitos, configura-se como a constante fuga desse método moderno. São desafios de ações para se fazer um uso profano do que outrora fora um instrumento de sacralização do conhecimento e da formação.

\section{Referências}

AGAMBEN. G. Homo sacer: o poder soberano e a vida nua I. Belo Horizonte: Editora UFMG, 2002.

. A linguagem e a morte: um seminário sobre o lugar da negatividade. Belo Horizonte: UFMG, 2006.

. O que é o contemporâneo? E outros ensaios. Chapecó, SC: Argus, 2010.

. Profanações. São Paulo: Boitempo, 2007.

. Nudez. Lisboa: Relógio D’Água Editores, 2010.

. Meios sem fim: notas sobre a política. Belo Horizonte: Autêntica Editora, 2015.

ARENDT H. Entre o passado e o futuro. 6. ed. São Paulo: Perspectiva, 2009.

ARISTÓTELES. Política. Lisboa: Veja, 1998.

ASSMANN, H. Reencantar a educação: rumo à sociedade aprendente. Petrópolis: Vozes, 1998.

ASSMANN, H.; MO SUNG, Y. Competência e sensibilidade solidária: educar para a esperança. 2. ed. Petrópolis, RJ: Vozes, 2001.

BATESON, G. Metadiálogos. Trajectos. 2. ed. Lisboa: Gradiva, 1989. 
CANDIOTTO, C.; D’ESPÍNDULA, T. S. Biopoder e racismo político: uma análise a partir de Michel Foucault. Intertesis - Revista Internacional Interdisciplinar, v. 9, n. 2, jul./dez. 2012.

CASTAÑEDA, C. A arte do sonhar. Rio de Janeiro: Nova Era, 2007.

DÍAZ, M. Foucault, docentes e discursos pedagógicos. In: SILVA, Tomaz (Org.). Liberdades reguladas. A pedagogia construtivista e outras formas de governo do eu. Petrópolis: Vozes, 1998. p. 14-29.

FOUCAULT, M. História da sexualidade I: A vontade de saber. 13. ed. Rio de Janeiro: Editora Graal, 1999.

. Em defesa da sociedade. Curso no Collège France (1975-1976). São Paulo: Martins Fontes, 2005.

. Segurança, território, população: curso dado no Collège de France (1977-1978). São Paulo: Martins Fontes, 2008. . Microfísica do poder. Rio de Janeiro: Edições Graal, 2009.

MACHADO, R. Introdução: por uma genealogia do poder. In: FOUCAULT, M. Microfísica do poder. Rio de Janeiro: Graal, 1992.

MARCONI, M. A.; LAKATOS E. M. Metodologia científica. São Paulo: Atlas, 2008.

MORIN, E. Introdução ao pensamento complexo. 3. ed. Lisboa: Instituto Piaget, 2001. . A cabeça bem feita: repensar a reforma, reformar o pensamento. 8. ed. Rio de Janeiro: Bertrand Brasil, 2003.

Recebido em: 6/6/2016

Aceito em: 8/8/2016 